\title{
Confessional Clamour and Intellectual Indifference
} Religion and Philosophy in the Wake of Descartes's New Method

\author{
Yoshi Kato \\ Rikkyo University, Tokyo, Japan \\ y-kato@rikkyo.ac.jp
}

Han van Ruler

Erasmus University Rotterdam, Rotterdam, The Netherlands vanruler@esphil.eur.nl

\section{Introduction}

Seventeenth-century Europe witnessed the beginning of a parting of ways between science and philosophy in what, for better or for worse, we call the 'Scientific Revolution.' The same century also saw a break-up between philosophy and theology, between naturalistic and religious ways of thinking. While Western philosophy would only gradually be losing its decision-making rights on questions of natural knowledge, Christian theology much more quickly lost the power of claiming philosophy as its 'handmaiden' in support of the truths of revelation.

These two developments were, of course, related, and this special issue of Church History and Religious Culture is about the impact and after-effects of one particular player in both fields: the new philosophy that introduced a new 'method' and new criteria for philosophising alongside ground-breaking initiatives in science and mathematics. Indeed, Descartes's publications would spur a host of genuinely scientific initiatives in such applied fields as optics, physiology, and medicine, as well as theoretical reflections on epistemology, physics, ethics, and metaphysics, which together would more or less define the new field of philosophical enquiry. Almost immediately, however, relations between philosophy and the venerable field of theology would become tense, with theological attacks being launched against Descartes from Jesuit as well as Calvinist quarters from the early 1640 onwards.

Fierce polemics forced all philosophers and theologians to position themselves in the conflict between philosophy and theology, or to provide good reasons for not doing so. While it may be presumed that these seventeenth- 
century intellectual troubles ultimately contributed to the fact that ecclesiastical authorities lost their hold on European minds, philosophers such as Descartes, Spinoza, Locke, and others were still very much aware of the presence of the Church and its orthodox shaping of faith and practice, regardless of their confessional stance or geographical location. At the same time, early modern publishing culture allowed philosophical ideas to spread rapidly, and even if philosophers were convinced that their ideas were perfectly orthodox, they still had to adapt their style of writing so as not to stir up theological controversy, or be deemed a threat to the health of the body of Christ. Some did this with a certain degree of success; others tried, but were considered highly unorthodox-or were even condemned as heretics.

The complexity and diversity of the various theological reactions to the new philosophy, was the primary theme of the academic conference "Orthodoxy, Heresy, and Indifference: Religion and Philosophical Practices in the Seventeenth Century." The conference was organized by the editors of this volume and held at Erasmus University Rotterdam on 25 and 26 January 2019, with the sponsorship of Erasmus School of Philosophy and the Japan Society for the Promotion of Science. Indeed, many of the papers in this volume were originally presented at the conference, but the discussions during and after the conference gave the editors a great opportunity to reflect anew on how philosophy as such ended up redefining its own place in relation to the impact of Descartes's philosophy and eventually found its rightful place between theology and science. The present volume is a result of these reflections.

Over the past decades, especially as a result of Theo Verbeek's research into what have meanwhile become standard reference points such as 'the Utrecht Crisis,' 'the Leiden Crisis,' and the background to some of Descartes's polemical works like the 1642 Letter to Dinet, a huge amount of new scholarship on the ensuing Streit der Fakultäten both within and without the Dutch Republic has added to our understanding of the seventeenth-century background to subsequent Enlightenment positions on reason and faith. The editors are very pleased that, for this volume, Theo Verbeek has been willing to contribute a chapter that engages the two main characters who sparked philosophical warfare at Utrecht during the first public crisis surrounding Cartesianism: Descartes and Voetius.

Verbeek's article reflects on how Descartes himself looked back on his confrontation with Voetius from a moral and political viewpoint and explores the 
way in which Descartes's experience with theological strife may have shaped his own views on morality and public dispute. Distinguishing two different types of learning, Descartes not only contrasted Voetius's use and misuse of bookish knowledge (doctrina) to the honest forms of self-formation of the eruditus, but thereby also anticipated his later analysis of the positive and negative effects of passions as well as the morality of 'generosity' (generosité), both of which are found in Les passions de l'âme of 1649. Indeed, according to Verbeek, Descartes devised his moral theory on the basis of the contrast between a dedicated attitude of kind-heartedness and a cowardly form of self-importance, the latter of which neatly matched the attitude he had earlier criticised in Voetius. Thereby inaugurating the view that "all political philosophy should be based on a theory of the passions," Descartes, according to Verbeek, was also probably the first philosopher to identify "a theologico-political problem."1

Such observations on the early modern development of philosophical and political thought may once again confirm the historical impact of Descartes's clash with orthodox theological positions, but coming from Descartes himself, they also indicate to what extent he remained insensitive to Voetius's insistence that he revise his views and bend to the demands of dogma. Descartes, personally, seems not in any way to have wavered, just as he would consistently advise his one-time Utrecht ally Henricus Regius to keep a distance from theological debate, but nevertheless to hold on to his philosophical views.

Descartes's indifference to theological admonition is a striking fact in itself and is a subject that will be developed in further chapters. Meanwhile, his controversy with Voetius could work as a warning sign for others. Whereas Descartes kept faithful to his own views whilst trying to steer free from theological matters, outsiders would have to determine their own position vis-à-vis potential points of conflict between philosophy and religion. Addressing the theological room for manoeuvre for philosophy immediately after Descartes, Sarah Hutton's article will take us over the English Channel and discuss the question of "resetting of the relationship of philosophy with religion" in the works of Henri More, Ralph Cudworth, and Anne Conway, all of whom held heterodox theological views, but for whom philosophical and religious truths were "deeply intertwined and who assumed the compatibility of reason and faith."

Where More sought to fortify theology, Cudworth ostensibly fought atheism, and Conway aimed to devise a philosophy consistent with 'true piety.' Nev-

1 See below, 155 .

2 See below, 159 . 
ertheless, their Platonism, as well as their criticism and reworking of themes in Descartes, brought all three philosophers to positions as much driven by sincere religious concerns as they were recognizably heterodox in respect of accepted Christian dogma. Paradoxical as this may seem, it nevertheless confirms Hutton's suggestion that it may be impossible to "answer with any certainty" such questions as "whether there is a direct relationship between philosophy and religious heterodoxy and atheism" - whether, indeed, philosophy as such undermines religion, or, rather, heterodox beliefs induce a certain type of philosophising; whether philosophers attacking others were consciously trying to conceal some of their own beliefs; or whether protestations of religious commitment more generally worked as a decoy to avoid a suspicion of heresy. ${ }^{3}$

If at all answerable, such questions call for a further demarcation of the terms and concepts themselves with which we are wont to approach seventeenthcentury conflicts between philosophy and theology. In another pair of articles related to what such terms as 'orthodoxy,' 'heterodoxy,' and 'heresy' may mean, we return to the Dutch context, with a view to answering these questions both from a theological and a philosophical perspective. Curiously enough, as Aza Goudriaan explains in his article on the concept of 'heresy,' charges of heresy were almost absent. For seventeenth-century authors, the term 'heresy' concerned theological topics only, and was primarily used for describing a traditional set of more or less well-developed positions on the Christian creed that deviated from Church dogma in early Christianity. Even when early modern Christians held heterodox views, they were said to lean towards or to accept some heresy, rather than called heretics themselves. The above-mentioned Voetius, for example, argued that philosophical positions, too, might 'smack of heresy,' or might even be counted as heresies if they belonged to theology as well, but he does not appear to have been thinking especially of Descartes. For his professed allegiance to the Roman Catholic Church, Descartes himself could not count in any way as a heretic, and was, accordingly, rarely associated with heresy, even though critics who were not theologians themselves might also apply the term to philosophers.

Views on philosophical freedom were slightly broader than might be expected in other ways as well. In fact, as Henri Krop argues in an article relating

3 See below, 158 . 
the question of orthodoxy to philosophical freedom, religious orthodoxy, such as it was defined in the case of the Reformed Churches at the Synod of Dordt, was not thought to be dependent on any specific philosophical background. Here again, Voetius showed an interest in philosophy that seems to have been sharper than usual, but even he urged for moderation and tolerance as well as for the freedom openly to discuss issues of biblical interpretation.

The only thing philosophy was banned from doing was to undermine theology. In the case of Descartes, however, Voetius's Leiden opponent Abraham Heidanus actually contended that it was Descartes's philosophy that offered a type of philosophising consistent with orthodox Calvinism. With respect both to the understanding of free will and to the explanation of the origin of sin, Heidanus argued that Descartes's analyses of judgement and of the workings of the human body supported Calvinist dogma. No wonder, then, that when Leiden University's governors forbade any discussion of specific Cartesian positions, Heidanus saw this as an infringement not just of the freedom to philosophise, but in fact of ecclesiastical liberties. Already well into his seventies, Heidanus would be fired from his post by the University to set an example for others, but he would remain highly regarded alongside his Utrecht rival Voetius as one of the leading lights of the Calvinist faith within the Dutch Reformed Church itself.

\section{The Autonomy of Philosophy}

In view of such conflicting appraisals, the question becomes pertinent for what reason Descartes's philosophy might be religiously or theologically problematic at all. In an article contrasting Descartes's method to scholastic metaphysics, Han van Ruler argues that a significant aspect of Descartes's philosophical strategy was to avoid the need to give a causal interpretation to such concepts as God, nature, and mind. Focusing on the concept of 'substance,' the article explores how even fellow anti-Aristotelians, as well as Cartesians and non-Cartesians after Descartes, would remain closer to scholastic theory than Descartes himself in their metaphysical quest to single out causal factors of natural change. Chasing the notion of substance from the explanations of natural philosophy, and thereby effectively excluding the notion God, the discipline of philosophy could no longer back up theological notions of divine intervention. Limiting himself to a problem-solving type of natural philosophy and thus restricting himself to a morally and theologically 'neutral' field of philosophising, Descartes, according to Van Ruler, thereby supplied a method that not only contributed to the seventeenth-century emergence of 
non-metaphysical ways of inquiry, but also fundamentally challenged the status of theology as a science.

Inherent conflicts within the post-Cartesian philosophical triad of metaphysics, science, and theology also come to the fore in Michael Jaworzyn's article on the Dutch Cartesian and Calvinist renegade Caspar Langenhert. Indeed, Langenhert's position is difficult to probe, as it is awkwardly inharmonious in itself. Having renounced Calvinism apparently for its harsh rejection of free will, Langenhert would exchange the Dutch provincial capital of Zwolle for Paris, where he was to develop an egomet metaphysics - a metaphysics accepting only the existence of God and ego-that in fact included a denial of human freedom. Aware of the many changes brought about by the new philosophy, Langenhert seems to have opted for a metaphysics that depicts God in almost Berkeleyan fashion, with theology adding hypotheses that go beyond the restricted domains of human knowledge. In such a scheme, theology and metaphysics are presented as complementary domains not literally in conflict with each other. At the same time, Langenhert's 'Geulincx-inspired' conception of human knowledge seems to turn upside down intuitive notions of intelligibility with respect to the philosophical and the religious, with religion teaming up with common sense, whilst philosophy and metaphysics, though functioning as the ultimate domains of certainty and truth, come to represent the limited viewpoints procured by human intellection.

Despite Descartes's declarations of philosophical neutrality and Langenhert's attempt at a compromise, Cartesian natural philosophy was sure to influence not only the traditional understanding of God's influence in natural change, but in fact the main body of traditional religious perceptions and sensitivities. This aspect comes out most pointedly in philosophical standpoints that many, Cartesians and anti-Cartesians alike, as well as later scholars reflecting on them, would come to see as 'radicalisations' of Cartesian doctrine.

In his contribution on the notion of God and the interpretation of miracles, Yoshi Kato has offered a clear historical example of the mechanisms of radicalisation. Comparing the views of the German-Dutch Cartesian Johannes Clauberg on these questions to those of Benedictus de Spinoza, Kato's reconstruction suggests a strikingly close parallelism of argumentative steps in both philosophers. Not only does Kato's detailed analysis recreate the story of the emergence of Spinozism from a Cartesian intellectual background, it also implies that what defines 'radicalisation,' at least in this case, paradoxically 
involves not the addition of new arguments, but rather the absence of doctrinal qualifications. Contrary to Clauberg, who in philosophising might have felt somewhat obliged to the ecclesiastical authority, Spinoza had no similar obligation, nor felt any need, to affix theologically inspired addenda to his naturalist interpretations. Kato's reconstruction of the link between Spinoza's and Clauberg's positions on God and miracles thus illustrates in very concrete terms how the intended religious neutrality of Cartesian natural philosophy was vulnerable to being used as philosophical dynamite if replaced within a religious context by a religiously indifferent author like Spinoza.

Spinoza is known to have formed part of a "radical scene" of Amsterdam friends mainly made up of former students of Leiden University who met in the 166os to discuss philosophical, religious, and social issues. ${ }^{4}$ One of the most assertive of these writers on inflammatory subjects, is Adriaan Koerbagh, whose wretched plight was that he would die in prison for having tried to publish his views - a plight that must have made a huge impression on Spinoza. In a contribution dedicated to the radical themes Koerbagh discussed in his two major works of 1668, Sonja Lavaert explains that the Amsterdam thinker is a representative of "leftist" and "democratic republicans" who linked "the Hobbesian naturalism and exposure of language misuse" to a political agenda completely at odds with Hobbes's own political views. As Lavaert describes it, Koerbagh's plan was to "enlighten the people through the translation of legal, theological, and philosophical concepts into common language,"5 a strategy that linked up with the linguistic work of another Cartesian radical, Lodewijk Meyer, also a well-known member of the Amsterdam circle of friends, but became an instrument of demystification and even of ridiculing religious doctrine in Koerbagh.

In comparison to Spinoza, Koerbagh's own particular brand of indifference to dogma thus included a deliberate, more explicit, and well-directed attack on religious conceptions. Such deconstruction and social interpretation of accepted views also included a more pointedly politicised notion of their effect on human relations of power. Demonstrating a more straightforwardly Hobbesian outspokenness in its criticism of ecclesiastical power and also a less reverent rendition of philosophical insights than the one we find in Spinoza, Koerbagh's concomitant plea for an unrestricted freedom of speech could not prevent him from being arrested and sentenced to the harsh prison sentence that no doubt caused his early death.

4 See below, $25^{8-259}$.

5 See below, 263 . 
The openly felt clash between religious and naturalistic interests that would subsequently effect European culture at large in what Paul Hazard famously called its Crise de conscience thus took immediate effect in the Dutch Republic with individuals being forced to be cautious about their allegiance to views known to have been defended and promulgated in 'Spinozist' circles. Spilling over the borders of the Seven Provinces, moreover, suspicions and indictments in the shadow of potential theologico-philosophical warfare would also emerge elsewhere.

The debate about whether or not a certain author should be read as a philosophical radical continues today with respect to a number of authors. In this volume, Andrea Strazzoni takes up the case of the Leiden University professor Burchard de Volder. Arguing that both extension and thought are infinite and numerically unique, De Volder struggled with the substantiality of Nature without ever seeming to have bent towards a Spinozist interpretation of either God or matter. As Strazzoni indicates, De Volder openly quoted Spinoza as a reliable source on Cartesian physics and seems in general to have been more sanguine towards his Amsterdam compatriot than most of his contemporaries. Yet it is exactly the lack of specific aspects of Spinozism like its substance monism and its biblical hermeneutics that may count as good reasons to situate De Volder in the tradition of Dutch Cartesianism rather than to be read as a Spinozist.

Whatever his own additional thoughts about Spinoza, De Volder's predicament was that of an early-modern academic who was forced to define his own position vis-à-vis the demands of religious orthodoxy, taking into account the precise demarcation of academic restrictions with respect to the freedoms of philosophy and theology. Whilst Leiden University was trying to keep a very delicate balance accommodating both religious and scientific sensitivities towards the end of the seventeenth century, the situation in German academia was still to become heated. Christian Wolff is an example of an academic whose life was very much affected by the strained relations between science and religion. Indeed, being banned from Halle in 1723, but returning as a result of political changes in 1740, Wolff may count as a philosopher whose career would be tossed back and forth on the waves of philosophical and religious tensions. As Dino Jakušić explains in the final article of this volume, Wolff transformed his personal experience into a theoretical position on 'philosophical servitude'-a concept he introduced for describing a situation in which the free application of philosophical method is hampered.

Arguing this philosophical method is basically a way of procuring and guaranteeing certainty "by inferring conclusions with legitimate sequence from cer- 
tain and immutable principles," ${ }^{6}$ Wolff in fact links up with Descartes's original aim of trying to define the domain of what may count as 'scientific.' Wolff gives a pointedly 'Euclidian' interpretation to this method, arguing at the same time that it is only by historical coincidence that we associate it with mathematics.

Wolff's most significant contribution to the conflict between science and religion, according to Jakušić, is the way he distinguished between the dogmas that may serve as building blocks for propositions in the deduction of truth and the hypotheses that only serve to further scientific investigation. Reflecting on the Galileo affair in particular, Wolff pointed out a way to bypass theologicophilosophical conflict—or, rather, to argue that the apparent conflict is in fact illusory. Since any opposition between true propositions and probable postulates can only be read as a conflict if one wishes to compare apples to oranges, there is indeed no conflict, according to Wolff. The gist of the matter is, that not only philosophical hypotheses may change, but theological hypotheses as well, most notably all hypothetical interpretations of Scripture.

\section{The Effect of the New Domain}

With Wolff's conclusion, the freedom to philosophise was coupled with a notion of certainty that provided for mutual adaptations of beliefs across the disciplines. Jakušić concludes that Wolff thereby presented a form of 'optimism' that was quickly to be overtaken by the Kantian notion of the limits of pure reason. Yet with respect to the conflict between science and religion, Kant's idea of a stalemate in practice comes very close to Wolff's. Uncompromising in one sense, yet diplomatic in another, Wolff's position may also be linked back to Descartes. Indeed, both Descartes and Wolff anticipate Kant in arguing for the possibility of a separation, along with a mutual understanding between science, philosophy, and religion.

Whether or not this left much room for philosophy itself to establish a worldview of its own, Descartes and Wolff each in their own ways contributed to the establishment of a domain of human knowledge in which certitude might reign independently of religious conflict. Ascertaining the boundaries of what is scientifically reliable and what is thought to lie outside the domain of knowledge susceptible to certainty, both authors tried to shield the new claims of reason in the field of natural philosophy against potential conflict. In this way, they

6 See below, 291. 
thought to have argued successfully against the clamour and intellectual pretence of orthodox and radical inflexibilities alike.

In less than a hundred years, the advance of natural science had thus been successful enough to establish the idea of a neutral field of human knowledge that might be developed independently of the hotly debated questions that had earlier fuelled the Utrecht Crisis. Because of the fast-growing authority of the new science, and the rearrangement of disciplinary hierarchies that came with it, philosophy was forced to reflect on itself and to adjust its interpretation of human knowledge in general. It is in this way that the history of modern Western philosophy was itself partly the result of a philosophico-religious conflict.

Along the way, the clash surrounding Cartesianism caused a host of alternative attitudes to the question of science and faith in-between Descartes and Wolff. If it may ultimately prove futile to try to give a definitive answer to Sarah Hutton's question concerning philosophy's inherent danger to religion, or to try to solve the historiographical problem she raises with respect to unearthing an early modern author's actual beliefs, the articles that follow will together present a choice of positions on the relationship between religion and science against the background of which such issues may be put to the test.

Orthodox theologians accused Descartes of transgressing the boundaries that radical interpreters of Descartes's method would wilfully violate. The confessional clamour in the wake of Descartes's philosophy accordingly reads as a history of the development of standpoints on the cognitive aspects of religion. The clamour in no way ended in 175 , but would continue to resonate in nineteenth-century debates on materialism and Darwinism, and yet again resounds in cultural clashes of the present day. The editors sincerely hope that this special issue of Church History and Religious Culture will further contribute to our understanding of similar clashes in the first century after the birth of modern science.

\section{Acknowledgments}

The editors would like to thank the general editors of Church History and Religious Culture for their willingness to collaborate with us in bringing the present project to completion. We would also like to thank all those who have contributed to this special volume and especially the participants of the conference who made the discussion of early modern philosophy and religion so stimulating. We are especially grateful to Wiep van Bunge, Davide Cellemare, James Clayton, Stefan Leicht, and E.A. Huppes-Cluysenaer, as well as to the staff and students of Erasmus School of Philosophy, Jamie van der Klaauw and 
Tomoko Higuchi in particular. We would also like to acknowledge the generous support of the Japan Society for the Promotion of Science (Grant Number: 16KKoO34) that not only made our conference possible, but also enabled one of the editors, Yoshi Kato, to spend an extended period as visiting scholar at Erasmus School of Philosophy from March 2018 to February 2019.

\section{Abbreviations}

At $\quad$ CEuvres de Descartes, ed. Charles Adam and Paul Tannery (Paris, 18971913 / 1964-1971 / 1996), followed by volume and page numbers.

csmk The Philosophical Writings of Descartes, ed. John Cottingham, Robert Stoothoff, Dugald Murdoch and Anthony Kenny (Cambridge, 19851991), followed by volume and page numbers. 